PREPARED FOR THE U.S. DEPARTMENT OF ENERGY, UNDER CONTRACT DE-AC02-76CH03073

PPPL-3593

PPPL-3593

UC-70

Neutral Beam Ion Confinement in NSTX

by

D.S. Darrow, E.D. Fredrickson, S.M. Kaye, S.S. Medley, and A.L. Roquemore

July 2001

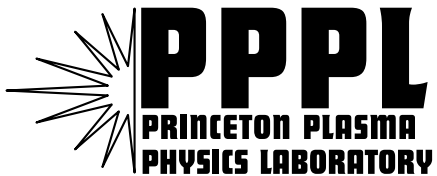

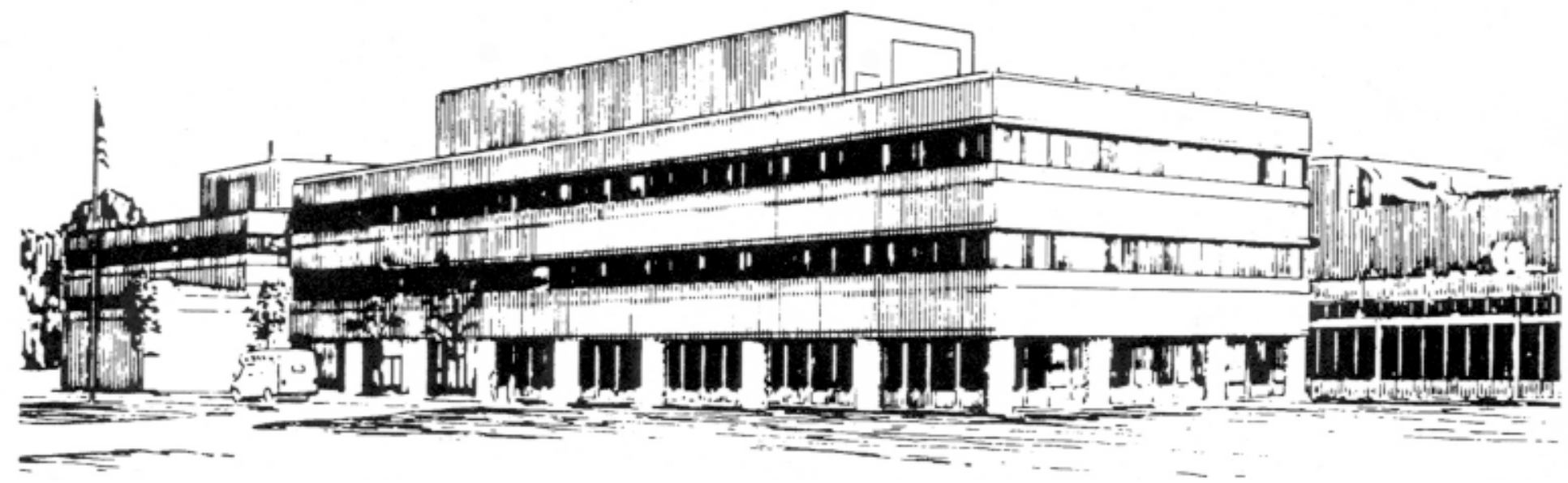

PRINCETON PLASMA PHYSICS LABORATORY PRINCETON UNIVERSITY, PRINCETON, NEW JERSEY 


\section{PPPL Reports Disclaimer}

This report was prepared as an account of work sponsored by an agency of the United States Government. Neither the United States Government nor any agency thereof, nor any of their employees, makes any warranty, express or implied, or assumes any legal liability or responsibility for the accuracy, completeness, or usefulness of any information, apparatus, product, or process disclosed, or represents that its use would not infringe privately owned rights. Reference herein to any specific commercial product, process, or service by trade name, trademark, manufacturer, or otherwise, does not necessarily constitute or imply its endorsement, recommendation, or favoring by the United States Government or any agency thereof. The views and opinions of authors expressed herein do not necessarily state or reflect those of the United States Government or any agency thereof.

\section{Availability}

This report is posted on the U.S. Department of Energy's Princeton Plasma Physics Laboratory Publications and Reports web site in Calendar Year 2001. The home page for PPPL Reports and Publications is: http://www.pppl.gov/pub_report/

DOE and DOE Contractors can obtain copies of this report from:

U.S. Department of Energy

Office of Scientific and Technical Information

DOE Technical Information Services (DTIS)

P.O. Box 62

Oak Ridge, TN 37831

Telephone: (865) 576-8401

Fax: (865) 576-5728

Email: reports@adonis.osti.gov

This report is available to the general public from:

National Technical Information Service

U.S. Department of Commerce

5285 Port Royal Road

Springfield, VA 22161

Telephone: 1-800-553-6847 or

(703) 605-6000

Fax: (703) 321-8547

Internet: http://www.ntis.gov/ordering.htm 


\title{
NEUTRAL BEAM ION CONFINEMENT IN NSTX*
}

\author{
D. S. Darrow, E. D. Fredrickson, S. M. Kaye, S. S. Medley, and A. L. Roquemore \\ Princeton Plasma Physics Laboratory, PO Box 451, Princeton, New Jersey 08543, USA
}

\begin{abstract}
Neutral beam (NB) heating in the National Spherical Torus Experiment (NSTX) began in September 2000 using up to $5 \mathrm{MW}$ of $80 \mathrm{keV}$ D beams. An initial assessment of beam ion confinement has been made using neutron detectors, a neutral particle analyzer (NPA) and a Faraday cup beam ion loss probe. Preliminary neutron results indicate that confinement may be roughly classical in quiescent discharges, but the probe measurements do not match a classical loss model. MHD activity, especially reconnection events (REs) causes substantial disturbance of the beam ion population.
\end{abstract}

\section{Introduction}

A major goal of spherical tokamak (ST) research is to obtain plasmas at high beta (i.e. $\beta_{\mathrm{T}}>10 \%$ ) via auxiliary heating. NB heating experiments in NSTX began in September 2000 using up to $5 \mathrm{MW}$ of $80 \mathrm{keV} \mathrm{D}$ beams from three co-injecting beam sources with tangency radii of $69.4 \mathrm{~cm}, 59.2 \mathrm{~cm}$, and $48.7 \mathrm{~cm}$ (designated A, B, \& C, respectively). In order to obtain high beta efficiently in an ST, the NB ions must remain well confined as they slow down and heat the plasma. The purpose of this paper is to provide an initial assessment of the quality of NB ion confinement in quiescent NSTX plasmas and to describe some observations of beam ion loss due to magnetohydrodynamic (MHD) instabilities.

In order to characterize beam ion confinement in NSTX, several diagnostics are used. These include a neutral particle analyzer ${ }^{1}$ (NPA) capable of looking at ions in both the thermal and suprathermal energy ranges, neutron detectors, and a Faraday cup based fast lost ion probe (FLIP). The NPA on NSTX utilizes a PPPL-designed E $\|$ B spectrometer which measures the energy spectra of $\mathrm{H}$ and D simultaneously with 39 energy channels per mass species and a time resolution of $1 \mathrm{msec}$. The neutron detectors on NSTX consist of both ${ }^{235} \mathrm{U}$ fission chambers and plastic scintillators. These give an absolutely-calibrated measure of the neutron emission from DD fusion reactions between NB ions and bulk plasma ions. The 
FLIP diagnostic ${ }^{2}$ measures the loss of ions with energies $>1 \mathrm{keV}$. It is located on the outer wall of the vessel, at the midplane, and has apertures at $\mathrm{R}=1.61 \mathrm{~m}, 1.63 \mathrm{~m}$, and $1.66 \mathrm{~m}$.

\section{Loss model results}

NB ion loss fractions have been modeled with the EIGOL code ${ }^{3}$, which follows the full gyro-orbits of particles but does not include the effects of collisions. The losses vary strongly with plasma current, being $\sim 15 \%$ lost at the standard current of $1 \mathrm{MA}$, and increasing rapidly to $\sim 40 \%$ at $0.5 \mathrm{MA}$. The loss fraction is relatively insensitive to plasma density, but does drop by a factor of three if the distance between the outer wall and the separatrix is increased from 5 to $15 \mathrm{~cm}$. Simulations also show a significant variation in the confined fraction depending upon which of the three beam sources is used. For a representative $1 \mathrm{MA}$ equilibrium, the loss fractions are $11 \%$ (A), 13\% (B), and 19\% (C). In addition, the loss fractions and neutron rates have been computed with the TRANSP code.

\section{Confinement in quiescent plasmas}

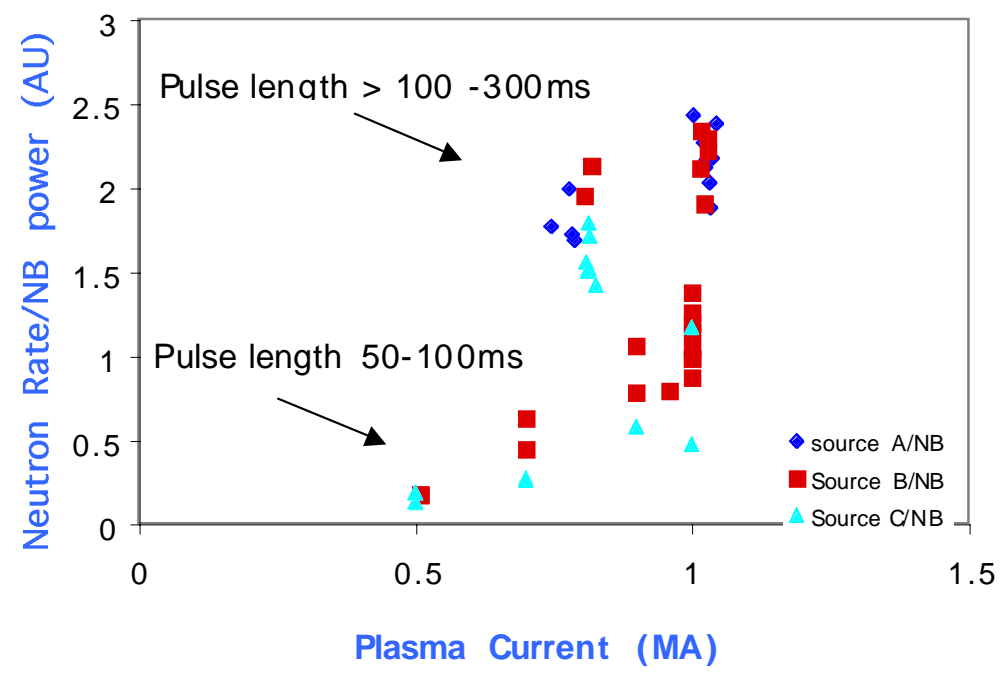

Figure 1: Neutron rate per unit neutral beam power as a function of plasma current for single NB source plasmas in NSTX. Better performance is seen as the current increases. In addition, sources A \& $\mathrm{B}$ always produce more neutrons than source $\mathrm{C}$.
Figure 1 shows the neutron rate as a function of plasma current and for beam lines of different tangency radii in NSTX. Two clusters of shots from two different campaigns are evident with distinctly different efficiencies of neutron production. Both data sets, however, show the trend of increasing neutron

yield with increasing current, as expected if the NB ion confinement was improving with higher current. In addition, the data show that the neutron production from source $\mathrm{C}$ is distinctly lower than that from the other two sources (which are both about equally efficient). This is also in qualitative agreement with the predictions of the EIGOL code. In addition, the measured neutron rate agrees with that from TRANSP calculations, which include both orbit 
loss and collisional effects, for the several shots that have been analyzed. Similarly, the neutron decay time after NB turn off usually matches that computed from the collisional slowing down of the NB ions, suggesting no large anomalous losses.

Measurements of the NB ion loss rate to the walls as a function of plasma current are

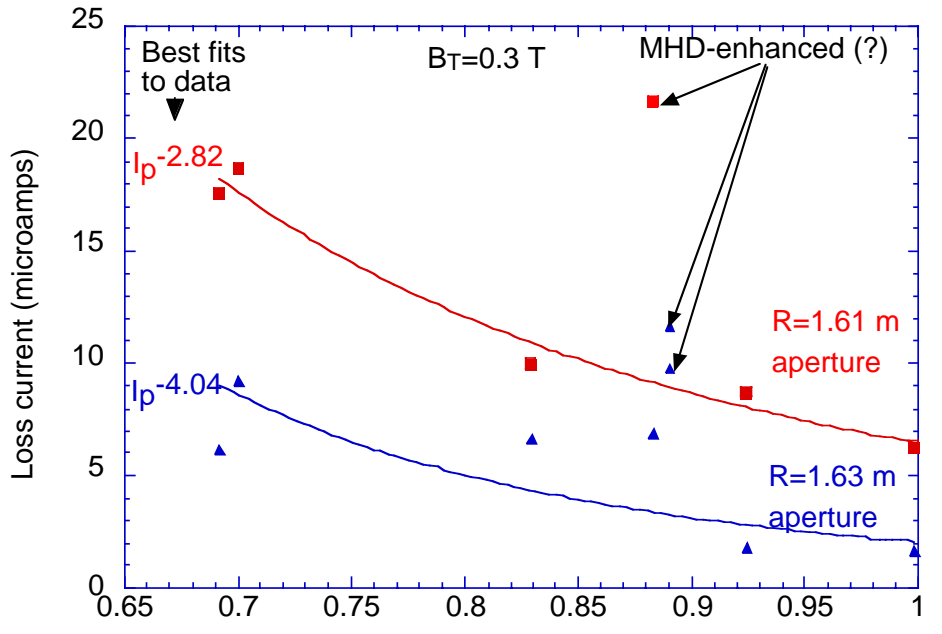

Figure 2: Measured beam ion loss currents at the NSTX midplane as a function of plasma current. Shown also are power law fits to the data and model results. depicted in Fig. 2. They

display the expected increase in loss fraction with decreasing plasma current. However, power law fits to the data show distinctly different exponents from the same fits to the model $\left(\mathrm{I}_{\mathrm{p}}^{-1.80}\right)$. A similar sort of variation is seen in the loss vs. $\mathrm{R}_{\tan }$ of the beam source, but again the variation of the measured loss is much larger than that predicted. In addition, the absolute magnitude of the loss is about ten times smaller than expected from EIGOL and TRANSP simulation results.

Our preliminary conclusion from the neutron measurements is that the loss of beam ions is consistent with the presence of only prompt orbit loss and collisional slowing down. Faraday cup loss measurements yield a more uncertain result as the loss levels are unexpectedly small and vary more strongly than the prompt loss model predicts. So, a more detailed and quantitative study is warranted.

\section{MHD effects on confinement}

An example of energetic ion behavior resulting from MHD activity is given in Fig. 3. Panel (d) shows a large $n=2$ mode arising at $0.26 \mathrm{sec}$ followed by an additional $\mathrm{n}=1$ mode at $0.32 \mathrm{sec}$ as determined from Mirnov coil measurements (b), which also shows that $\mathrm{q}(0)>1$ during this period. Onset of the $n=2$ mode leads to a decay of the energetic ion population $(\mathrm{E} \sim 5-80 \mathrm{keV})$ and consequently the neutron yield as shown in panel (d). Thermal ions (E $\sim 0.5-5 \mathrm{keV}$ ) are also lost during MHD activity producing a collapse in the ion temperature. The effect of RE activity (at the upticks in the plasma current in panel (a)) differs from that observed for MHD modes. In this case, prompt loss of the energetic ions occurs on a time 
scale of $\leq 5 \mathrm{~ms}$ while the thermal ions remain confined but are redistributed outboard from the core to a region of higher neutral density which increases the neutral particle flux and
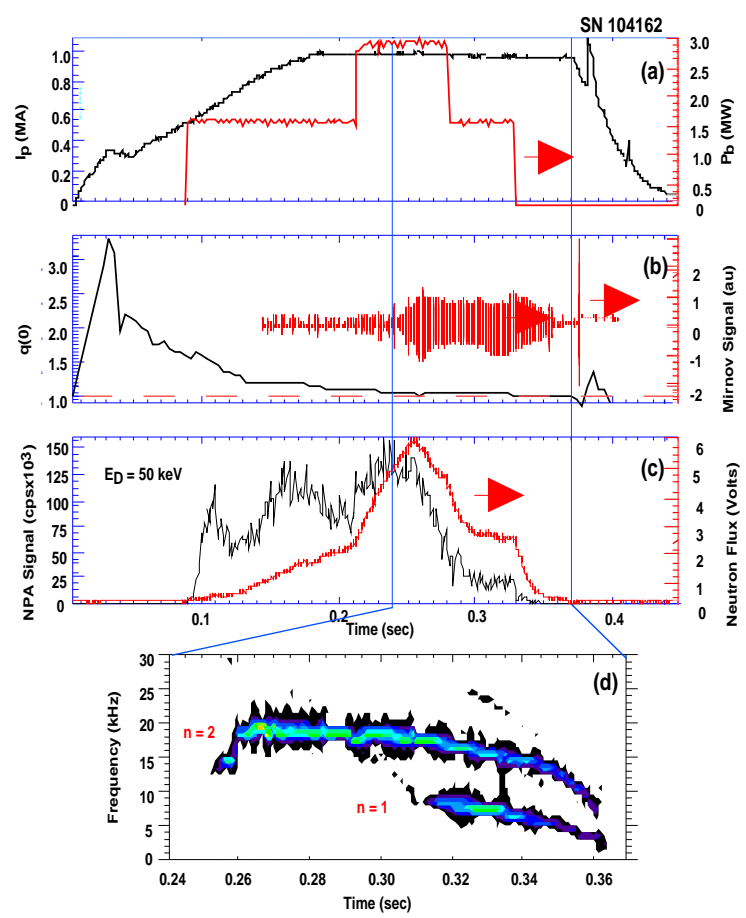

Figure 3: MHD activity (b \& d) reduces neutron yield and energetic $\mathrm{D}$ ion confinement (c). apparent $\mathrm{T}_{\mathrm{i}}$ measured by the NPA.

The neutron rate is observed to drop very rapidly when REs occur, indicating rapid loss of a large fraction of the NB ions. Simultaneously, the FLIP records large loss signals, starting a few ms before the plasma current spike. These, along with NPA data, indicate that REs can cause strong deconfinement of fast ions. Sawteeth crashes can also cause a substantial reduction in the neutron signal and cause large loss spikes on the FLIP. However, only a limited alteration of the NPA signal is seen.

\section{Summary}

An initial study of beam ion confinement in NSTX indicates that neutron rates produced by beam ions are generally consistent with those expected classically from prompt orbit loss and collisional slowing down. Some features of the beam ion loss measurement vs plasma current require further investigation to determine whether they can be reconciled with a classical ion loss model. MHD activity, especially REs, is observed to cause substantial redistribution and loss of beam ions in NSTX.

This work was supported by US DoE contract DE-AC02-76CH03073.

1. S. S. Medley, et al. Rev. Sci. Instrum . 69, 2651 (1998).

2. D. S. Darrow, et al., Rev. Sci. Instrum . 72, 784 (2001).

3. D. S. Darrow, et al., in Proceedings of the 26th EPS Conference on Controlled Fusion and Plasma Physics, Maastricht, The Netherlands, 14-18 June 1999. 


\section{External Distribution}

Plasma Research Laboratory, Australian National University, Australia

Professor I.R. J ones, Flinders University, Australia

Professor J oão Canalle, Instituto de Fisica DEQ/IF - UERJ , Brazil

Mr. Gerson O. Ludwig, Instituto Nacional de Pesquisas, Brazil

Dr. P.H. Sakanaka, Instituto Fisica, Brazil

The Librarian, Culham Laboratory, England

Library, R61, Rutherford Appleton Laboratory, England

Mrs. S.A. Hutchinson, JET Library, England

Professor M.N. Bussac, Ecole Polytechnique, France

Librarian, Max-Planck-Institut für Plasmaphysik, Germany

J olan Moldvai, Reports Library, MTA KFKI-ATKI, Hungary

Dr. P. Kaw, Institute for Plasma Research, India

Ms. P.J . Pathak, Librarian, Insitute for Plasma Research, India

Ms. Clelia De Palo, Associazione EURATOM-ENEA, I taly

Dr. G. Grosso, Instituto di Fisica del Plasma, Italy

Librarian, Naka Fusion Research Establishment, J AERI, J apan

Library, Plasma Physics Laboratory, Kyoto University, J apan

Research Information Center, National Institute for Fusion Science, J apan

Dr. O. Mitarai, Kyushu Tokai University, J apan

Library, Academia Sinica, Institute of Plasma Physics, People's Republic of China

Shih-Tung Tsai, Institute of Physics, Chinese Academy of Sciences, People's Republic of China

Dr. S. Mirnov, TRINITI, Troitsk, Russian Federation, Russia

Dr. V.S. Strelkov, Kurchatov Institute, Russian Federation, Russia

Professor Peter Lukac, Katedra Fyziky Plazmy MFF UK, Mlynska dolina F-2, Komenskeho Univerzita, SK-842 15 Bratislava, Slovakia

Dr. G.S. Lee, Korea Basic Science Institute, South Korea

Mr. Dennis Bruggink, Fusion Library, University of Wisconsin, USA

Institute for Plasma Research, University of Maryland, USA

Librarian, Fusion Energy Division, Oak Ridge National Laboratory, USA

Librarian, Institute of Fusion Studies, University of Texas, USA

Librarian, Magnetic Fusion Program, Lawrence Livermore National Laboratory, USA

Library, General Atomics, USA

Plasma Physics Group, Fusion Energy Research Program, University of California at San Diego, USA

Plasma Physics Library, Columbia University, USA

Alkesh Punjabi, Center for Fusion Research and Training, Hampton University, USA

Dr. W.M. Stacey, Fusion Research Center, Georgia Institute of Technology, USA

Dr. J ohn Willis, U.S. Department of Energy, Office of Fusion Energy Sciences, USA

Mr. Paul H. Wright, Indianapolis, Indiana, USA 
The Princeton Plasma Physics Laboratory is operated by Princeton University under contract with the U.S. Department of Energy.

\author{
Information Services \\ Princeton Plasma Physics Laboratory \\ P.O. Box 451 \\ Princeton, NJ 08543
}

Phone: 609-243-2750

Fax: 609-243-2751

e-mail: pppl_info@pppl.gov

Internet Address: http://www.pppl.gov 